\title{
The Bandgap of InN Gave Rise to Animated Discussion at IWN-04
}

The 2004 International Workshop on Nitride Semiconductors (IWN-04) was held July 19-23 at Sheraton Station Square by the Monongahela River in Pittsburgh, Pa. Workshop Chair Randall Feenstra (Carnegie Mellon University) worked closely with the Program Committee, chaired by Tom Myers (West Virginia University), and the International Advisory Committee, chaired by Russell Dupuis (Georgia Institute of Technology), to put together an extensive program with topics ranging from recent developments in ultraviolet light-emitting diodes (UV LEDs) and high-electron-mobility transistors (HEMTs) to advances in growth and characterization techniques, to the bandgap of InN. The program encompassed two parallel sessions with eight invited talks and more than 400 oral and poster presentations delivered to 500-plus attendees. Published proceedings of the workshop will appear in a special volume of physica status solidi.

The workshop began with plenary talks on UV LEDs (A. Khan, South Carolina University) and ferromagnetism in III-V and III-N semiconductors (H. Ohno, Tohoku University). Khan reported on how innovations such as the group's novel growth technique of migrationenhanced metalorganic chemical vapor deposition and the use of a new micro-

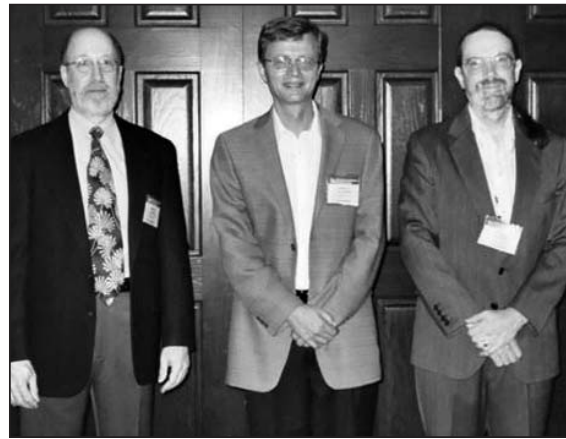

reviewed the properties of III-V-based magnetic semiconductors, describing, for example, how magnetic properties can be electrically controlled in such materialsmagnetization reversal can be obtained through current-induced domain wall propagation.

In the session on lasers, J. Heffernan of Sharp Laboratories Europe, U.K., gave a detailed report on the company's pioneering work on InGaN multiple-quantumwell laser diodes grown by molecularbeam epitaxy (MBE). He reported that their threshold voltage is now down to
Randall Feenstra (Carnegie Mellon University), chair of the 2004 International Workshop on Nitride Semiconductors (center), meets with Program Committee chair Tom Myers of West Virginia University (right) and International Advisory Committee chair Russell Dupuis of Georgia Institute of Technology (left) during the welcome reception.

pixel geometry have resulted in the successful production of LEDs emitting down to $250 \mathrm{~nm}$. External quantum efficiencies of such deep-UV LEDs are still low due to dislocations in the AlGaN; however, future progress is expected to open up yet another billion-dollar industry to the nitrides, that of biomedical sensors. Ohno $10 \mathrm{~V}$, with a current density of $7 \mathrm{kA} \mathrm{cm}^{-2}$ (200 ns pulses; duty cycle, $10 \%$ ). Improved thermal management should lead to further improvements in performance, he said. Advances in high-power microwave devices also attracted attention-in particular, Cree's spectacular results from field plate devices, with over $30 \mathrm{~W} / \mathrm{mm}$ continuous-wave power density and over $50 \%$ power added efficiency. J. Speck of the University of California-Santa Barbara discussed the advances in MBE for the growth of GaN-based electronic devices, with results equal to or improving upon other growth techniques. M. Manfra of Lucent Technologies continued this theme, reporting on high-power GaN/AlGaN/GaN HEMTs operating at 2-25 GHz grown by plasma-assisted 


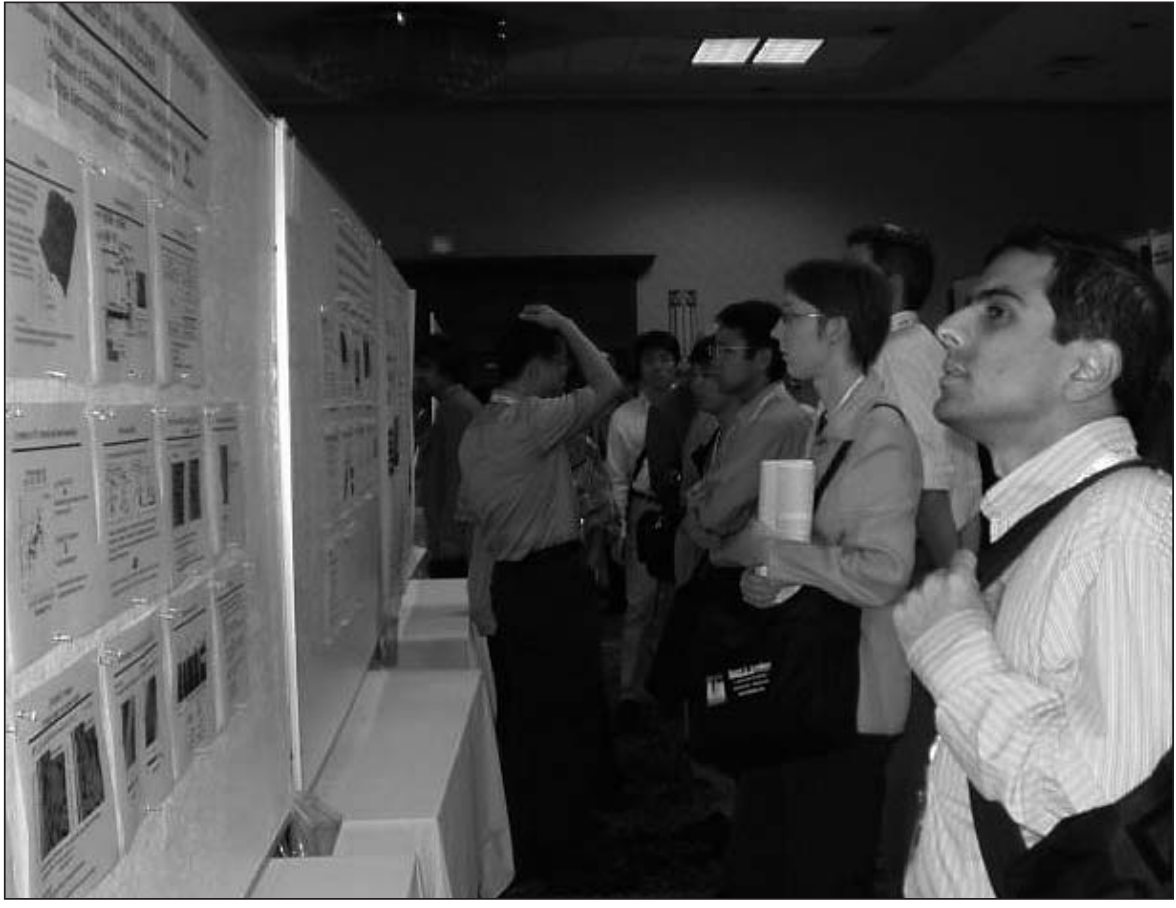

Three evenings were reserved for poster presentations.

MBE. Y. Kawakami (Kyoto University) discussed recombination mechanisms in InGaN deduced from temporally and spatially resolved luminescence spectroscopy where the impressive results were produced using multimode scanning near-field microscopy. M. Kuball of the University of Bristol presented his innovative, high-spatial-resolution microRaman temperature measurements of nitride devices (field-emitting transistors and light-emitters). A. Dadgar of the University of Magdeburg, Germany, discussed work concerning the heteroepitaxy of GaN-based devices on silicon substrates.

Animated discussions ensued throughout the conference on the subject of the bandgap of InN. On Wednesday, three intense sessions opened with an invited talk from O. Briot of GES-CNRS, France. He noted that the key to realizing highquality material is not simply to produce a

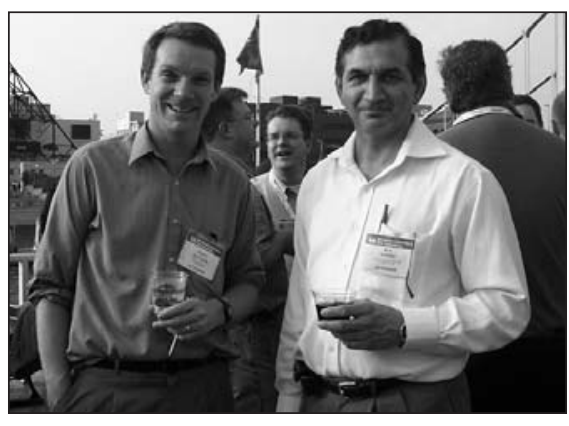

Scott Butcher of Macquarie University, Australia, and Mohamed-Ali Hasan of North Carolina University, USA, enjoy the sunset cruise offered during a break from the workshop.

lattice-matched substrate, but that wetting to the substrate surface is also important, as surface tension determines whether two- or three-dimensional growth is obtained. He presented evidence for a band-to-band transition of $\sim 1.2 \mathrm{eV}$. However, his talk was followed by a series of talks presenting data indicating a bandgap of between $0.59 \mathrm{eV}$ and $0.7 \mathrm{eV}$. There was therefore much to discuss at the evening Rump Session on InN, chaired by William Schaff of Cornell University; interest was high as the panelists took their seats. The plan of the evening was for panelists Friedhelm Bechstedt of FriedrichSchiller-Universität Jena, Germany; Wladek Walukiewicz of Lawrence Berkeley Laboratory, USA; Bo Monemar of Linköping University, Sweden (on behalf of Tatiana Shubina, of Ioffe Institute, Russia); Yasushi Nanishi of Ritsumeikan University, Japan; and Scott Butcher of Macquarie University, Australia, to give short presentations, after which the discussion would be opened to the floor. Butcher was halfway through the final presentation when the electricity in the building went off and discussion had to be postponed. A more subdued group reconvened the following evening. Valery $\mathrm{Yu}$ Davydov of Ioffe Institute, Russia, commenced the discussion with a presentation supporting a narrow bandgap for InN. The interpretation of available data is hotly contested and, not surprisingly, no definitive conclusions could be reached. It was agreed that $\mathrm{InN}$ is a difficult material to grow and its properties vary depending on how and where it is grown.

The workshop was sponsored by the U.S. Office of Naval Research, the Air Force Office of Scientific Research, and the Army Research Office. Financial support for student travel was provided by a grant from the National Science Foundation. In addition, the social events at the workshop, including a sunset cruise, were made possible through sponsorship by AIXTRON, Cree, Kurt J. Lesker, SVT Associates, EMCORE Corporation, and Veeco Instruments. These companies and many others displayed their products at the exhibit during the workshop.

CAROL TRAGER-COWAN University of Strathclyde

\section{MRS Future Meetings}

\section{FALL MEETING}

Nov. 29-Dec. 3

Exhibit: Nov. 30-Dec. 2

Boston, MA

\section{SPRING MEETING}

March 28-April 1

Exhibit: March 29-31

San Francisco, CA
2005 FALL MEETING

Nov. 28-Dec. 2

Exhibit: Nov. 29-Dec. 1

Boston, MA
2006 SPRING MEETING

April 17-21

Exhibit: April 18-20

San Francisco, CA 